\title{
Assessment of Seismic Resistance of a Ventilation Stack of a Reactor Building
}

\author{
Daniel Makovička ${ }^{1)}$ and Daniel Makovička ${ }^{2)}$
}

1) CTU in Prague, Klokner Institute, Prague, Czech Republic

2) Static and Dynamic Consulting, Kutná Hora, Czech Republic

\begin{abstract}
Stack structures are sensitive to seismic loads, as a rule, as their tuning (the spectrum of the lowest natural frequencies) corresponds with the frequency spectrum of excitation by seismic effects. The purpose of the paper is to show, on the example of an actual structure, the character of the response of the structure, the participation of individual response frequency components in the overall stress and strain state of the structure of this type incl. the methodology of the numerical analysis of the structure and the recommendations of relevant standards and codes. The paper is concerned with the assessment of seismic resistance of a stack structure incl. an analysis of respective reserves and the possibilities of resistance increasing.
\end{abstract}

\section{INTRODUCTION}

The ventilation stack proper (Fig. 1a) is fastened with bolts to the roof structure of a reinforced concrete building as a result of which the seismic load of the ventilation stack is modified by the transmission characteristics of the building. Seismic load, which propagates through the ground environment to the foundations of the building, is characterized in this particular case by the acceleration of $0.1 \mathrm{~g}$ for the horizontal movement component at foundation level and the acceleration of $0.07 \mathrm{~g}$ for the vertical movement component.

The seismic analysis of the whole system, comprising the foundation sub-base, the building and the ventilation stack, is an extensive problem. For this reason in engineering practice this system is usually divided into two subsystems: sub-base + building and ventilation stack. The first subsystem considers the influence of the stack structure on the roof of the building merely in terms of mass (not stiffness). The analysis of the stack in the second subsystem considers the actual roof stiffness and its actual dynamic response to seismic excitation, expressed e.g. by the response spectrum (Fig. 2). The degree of justification of the application of this simplification depends on the difference between the natural frequencies of the stack (Fig. 1b) and the natural frequencies of the building incl. its roof on top of which the stack is anchored.

The solution of the problem is based on the analysis of the response of the structure by the decomposition into the dominant natural frequency modes.

\section{DESCRIPTION OF STACK STRUCTURE}

The ventilation stack (Fig. 1a) is a double-skin steel segment structures consisting of five segments $10.200 \mathrm{~m}$ high and the foundation element $1.550 \mathrm{~m}$ high. The total stack height is $52.550 \mathrm{~m}$. The stack is provided with two platforms - the middle platform $20.550 \mathrm{~m}$ and the upper platform $49.130 \mathrm{~m}$ above the stack base level (the level of the stack contact with the roof of the building). The stack is provided with exterior steel ladder along its whole height with small platforms and railing at the level of individual segments. Between the middle and the upper platforms the stack shaft is provided with helical wind-breakers.

The inside diameter of the exterior cylindrical segment skin is $3.000 \mathrm{~m}$, the wall thickness is $12 \mathrm{~mm}$ in the first segment and $8 \mathrm{~mm}$ in the second to fifth segments. The interior segments have an inside diameter of $1.600 \mathrm{~m}$ and a wall thickness of $4 \mathrm{~mm}$. At the ends of individual segments the exterior and the interior segment skins are mutually connected with annular stiffeners of steel plate $16 \mathrm{~mm}$ thick.

The lowest stack segment is connected with the foundation element consisting merely of an exterior cylinder with horizontal and vertical stiffeners.

The foundation stack element (Fig. 1a) consists of two cylindrical parts. In the lower part $1.110 \mathrm{~m}$ high it is reinforced between the lower and the upper flanges with twelve pairs of trapezoidal plates $16 \mathrm{~mm}$ thick on the 
outside. The outer skin $12 \mathrm{~mm}$ plate proceeds from the lower flange up to the upper flange through the whole height of the foundation element. The foundation element is fastened to the reinforced concrete roof structure by means of twelve M90 foundation bolts placed in the axes of every pair of trapezoidal reinforcement plates.

The stack material has been considered as Class 37 standard structural steel of the S 235 strength category.
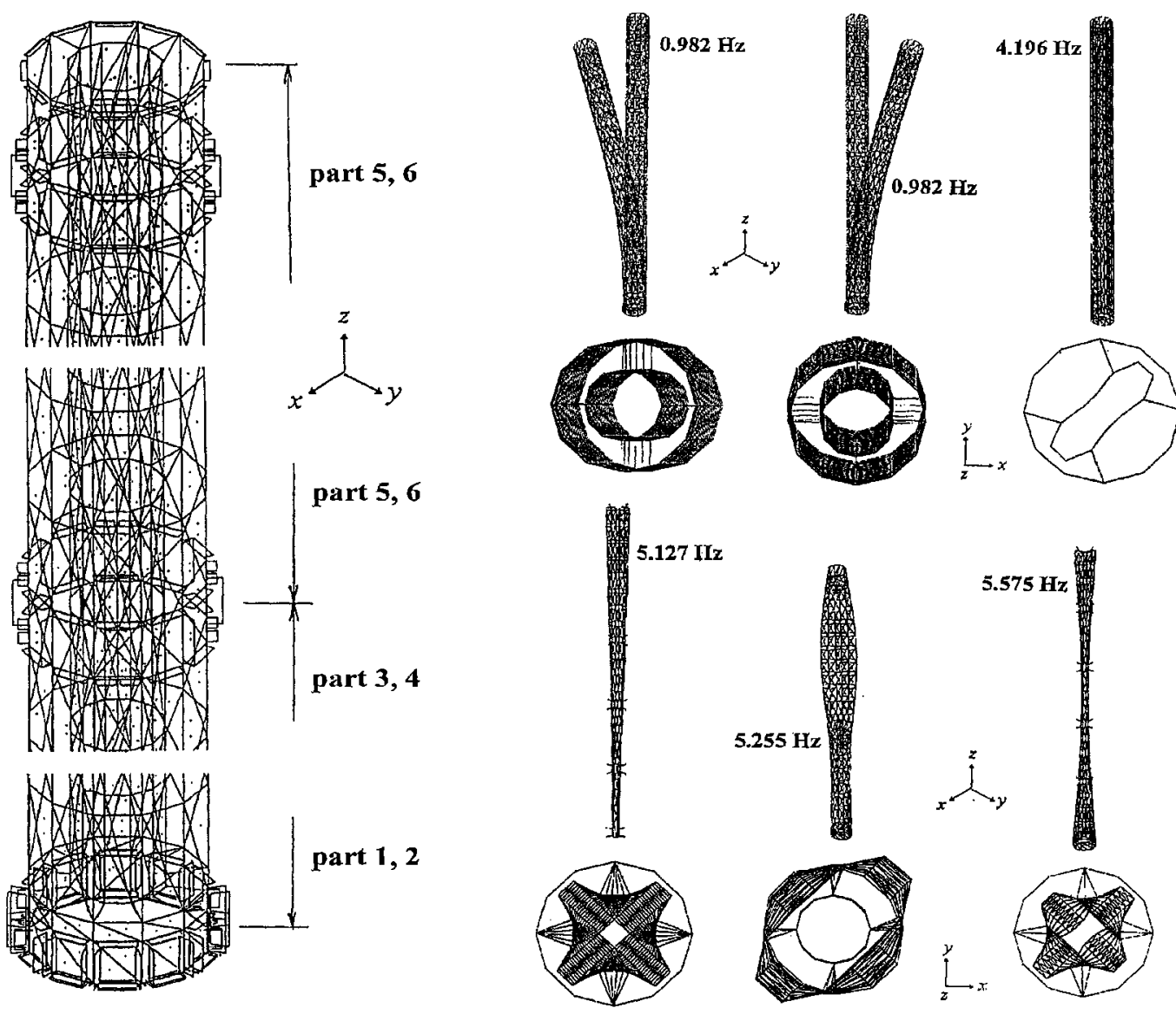

Fig. 1 a) Geometry of Ventilation Stack, b) Natural Frequency Modes

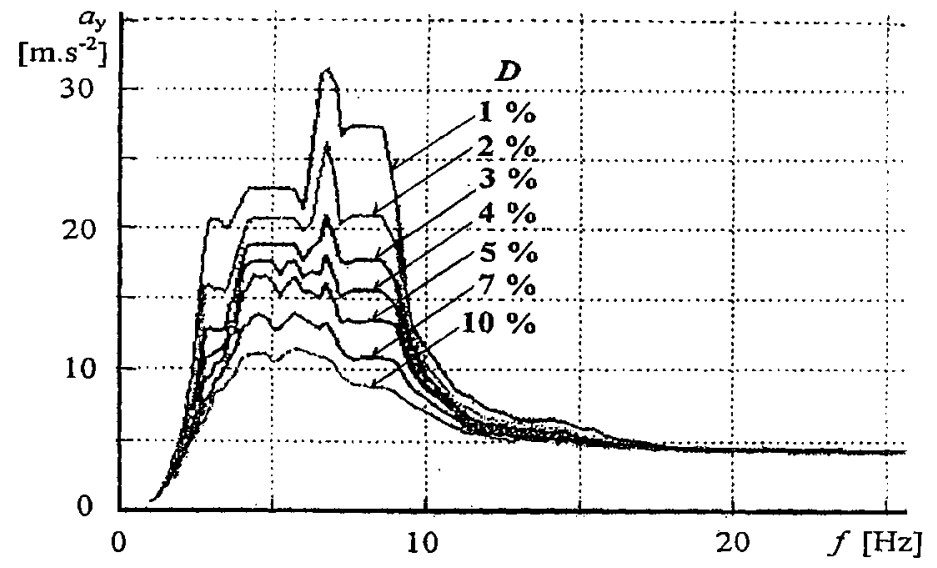

Fig. 2 Response Spectrum of Reactor Building Roof 


\section{ANALYTICAL MODEL}

The cylindrical skins were modeled per partes by plane wall plate elements (thin plates) of appropriate thickness. The stiffeners were modeled per partes by beam elements. The non-load-bearing elements (gallery floors, ladders, ladder cages, etc.) were replaced with concentrated masses, manifesting themselves both by their own weight and under seismic load by appropriate forces acting in the load direction $(x, y, z)$, respective. The analytical model is shown in Fig. la.

The damping of the steel structure in case of seismic excitation was considered conservatively at the rate of $3 \%$ of critical damping. (For seismic load it is possible to use up to $5 \%$ damping [3], although for standard loads, such as wind load, the damping of steel structures is usually considered at about $3 \%$, as a rule).

The foundation element of the stack bears on the roof structure by its lower flange. For the purpose of the analysis this bearing was simplified into elastic supports in all three directions of coordinate axes $(x, y, z)$ in the intersection point of the outer skin with the surface of the roof structure.

The kinematic excitation by seismic forces was considered as the effect of dynamically variable forces along the substitute elastic supports trajectory so as to eliminate (or permit only negligible) influence of the selected support stiffness or the natural frequencies of the structure as a rigid body on elastic support, corresponding with this stiffness, on the character of the response within the seismic excitation scope of the frequencies of interest, approx. up to $33 \mathrm{~Hz}$. This simplification results in the necessity of correcting the computed displacements and internal forces in the individual dominant frequencies of the response of the structure according to the actual frequency-dependent amplitude of seismic excitation (Fig. 2), corresponding with the excitation spectrum at the roof level.

\section{RESPONSE ANALYSIS}

The lowest natural vibration modes are shown in Fig. $1 \mathrm{~b}$. With regard to the almost symmetrical stack form with reference to the both horizontal axes $x$ and $y$ (the symmetry being disturbed by the ladder located on $x$ side) the corresponding natural modes are very close to each other on the frequency axis.

The figures showing the lowest natural vibration modes reveal that apart from the two lowest natural frequencies of the bending vibrations of the stack as a cantilever structure in the proximity of $1 \mathrm{~Hz}$ all other higher modes arise primarily from bending vibrations of the cylindrical structure of both skins in radial direction. Apart from the dominant bending modes also the axial vibration mode of the stack structure as a whole in the direction $z$ is significant, found in the vicinity of the natural frequency of $22.5 \mathrm{~Hz}$, and the mode combining the axial stack vibrations in direction $z$ with the stack bending at the frequency of $18.5 \mathrm{~Hz}$.

The computation of natural frequencies and modes is supplemented with computed diagrams of steady-state curves in Fig. 3 in the selected points of the foundation element in which the resonance frequencies manifest themselves with peaks (tops of the given relations). With reference to stack vibrations under seismic excitation the following frequencies are dominant :

a) for excitation in horizontal direction natural frequencies in the vicinity of

b) for excitation in vertical direction natural frequencies in the vicinity of

$1.0 / 5.1 / 14.5 \sim 16.0 / 26.5 \mathrm{~Hz}$;

$18.5 / 22.5 \mathrm{~Hz}$.

The dynamic computation of the response was made for excitation in horizontal direction $x$ (it was assumed, with a certain simplification, that the excitation in direction $y$ is the same as that in direction $x$ ) and for excitation in vertical direction $z$. The target of the computation was to ascertain the seismically significant low frequency interval of seismic excitation from 0 to $33 \mathrm{~Hz}$.

The computed displacement in supports corresponds with the stiffness $\mathrm{k}$ and the dynamic excitation force $\mathrm{F}$

$$
\mathrm{A}_{\text {comp }}=\mathrm{F} \cdot \mathrm{k}
$$

The given values of acceleration a (Fig. 2) at the building floor level as the function of frequency $f$ of stack support vibrations can be used for the determination of the actual amplitude vibration of the support A due to seismic excitation at the appropriate frequency $\mathrm{f}$

$$
A(f)=a /\left(4 \cdot \pi^{2} \cdot f^{2}\right)
$$

The correction factor $\xi$ for the respective frequency $f$ is 


$$
\xi(f)=A(f) / A_{\text {comp }}=a(f) /\left(4 \cdot \pi^{2} \cdot f^{2} \cdot A_{\text {comp }}\right)
$$

This correction factor is used for the necessary correction of the computed response (Fig. 3), e.g. in the displacements y

$$
y(f)=y_{\text {comp }}(f) \cdot \xi(f)
$$

The following Tables 1, 2 and 3 give the maximum amplitudes (after correction) of stresses, displacements at the individual height levels and structural parts of the stack and support forces. For easier description of the structure its individual load-bearing members (Fig. 1a) are numbered as follows: 1 - outside cylinder plate of foundation element, 2 - vertical pairs of foundation element stiffeners, 3 - exterior skin plates between foundation element and middle platform, 4 - interior skin plates between foundation element and middle platform, 5 - exterior skin plates between middle platform and stack top, 6 - interior skin plates between middle platform and stack top.

Maximum response value in individual frequency peaks for selected structural members of the stack are vector sums (RMS values; horizontal component is considered in a simplified manner as twice the sum of components in directions $x$ and $y$ ). For the maximum resultant amplitude $\mathrm{A}$, for instance, the formula was modified

$$
A_{\max }=\sqrt{A_{x}^{2}+A_{y}^{2}+A_{z}^{2}} \approx \sqrt{2 \cdot A_{x}^{2}+A_{z}^{2}}
$$

The above computation reveals that the dominant stress of the stack structure is due to horizontal excitation by the frequencies in the vicinity of $1.0 \mathrm{~Hz}$ and $5.1 \mathrm{~Hz}$, while the energy contribution of other frequency components above $15 \mathrm{~Hz}$ to the influence on response magnitude is practically negligible.

The highest stress has been found in the foundation element stiffeners, where the maximal stress in stiffeners attains approximately $\pm 240 \mathrm{MPa}$ (for Class 37 structural steel the yield point $f_{y}=235 \mathrm{MPa}$ ), while in the exterior cylinder plate only approximately $\pm 130 \mathrm{MPa}$. Under seismic load, therefore, the stress redistribution in the foundation element probably will take place due to plastic deformations in the highly stressed parts of stiffeners.

These stiffeners are loaded by a combination of the normal force and bending moments; therefore it is possible to apply the ductility factor to these extreme loads. This ductility factor is usually given in the respective codes and standards in dependence on the importance of the structure and its structural design with different safety margins. The Eurocode [3] permits the ductility factor ,for standard structures, unless the design brief provides differently" at the rate of 2.0 regardless of structural design of the structure subjected to seismic load. The US code [7] valid for power plant structures enables a more discerning application according to the type of structure (design of joints of structural members, material, importance of the structure, etc.) of the ductility factor to steel structures within the limits of 2.5 and 3.3. As the structure is considerably sensitive to seismic loads, we shall apply this ductility factor conservatively by approximately half of its permissible value, i.e. 1.6. The purpose of ductility factor application is to use linear elastic computation. The difference in the approach of both afore-mentioned standards consists in that the Eurocode [3] uses the ductility factor to correct the seismic load before the computation start, while the US codes [1] [7] permit the correction of the computed response and only for structural members loaded in bending and not for those loaded in compression or tension for which they stipulate the ductility factor of 1.0. In this respect the applied code [3] is on the safe side.

If we apply the afore-mentioned ductility factor of 1.6 to the most highly loaded stiffeners, we obtain the maximum stress in these stiffeners

$$
\sigma=\sigma_{\max } / 1.6
$$

The resulting stress in stiffeners $\sigma_{\max }$ (under linear simplification), consequently, is

$$
\sigma_{\max }=\sqrt{2 \cdot \sigma_{\mathrm{x}}^{2}+\sigma_{\mathrm{z}}^{2}}=\sqrt{\left[2 \cdot\left(40.6^{2}+207.1^{2}+7.8^{2}+2.2^{2}\right)+2.7^{2}+3.2^{2}\right]}=298.7 \mathrm{MPa}
$$

After multiplication by the ductility factor we obtain

$$
\sigma=298.7 / 1.6=186.7 \mathrm{MPa}
$$

It should be noted that there are twelve pairs of vertical stiffeners about the periphery of the foundation element and the maximum of the computed stresses has been attained in two pairs of stiffeners only, situated in the vertical 
plane in the direction of bending vibrations (e.g. in the plane $x z$ or $y z$, possibly in the diagonal plane between them, etc.). Consequently, even if these two stiffener pairs become plasticized, the remaining ten pairs are subjected to smaller loads within the elastic region of behaviour of their material, not necessitating the introduction of the ductile characteristics of the structure.

As it follows from Tables 1 and 2 the material of other structural members of the stack is stressed in the elastic region of their material deformation.

For the purpose of comparison of the dynamic stack response in case of a seismic event the principal stresses in the outer skin plate due to the dead weight of the structure are below $10 \mathrm{MPa}$ which is a very low level comparable with seismic effects.

Table 1. Stress $\sigma[\mathrm{MPa}]$ in Stack Parts

\begin{tabular}{|c|c|c|c|c|c|c|c|c|}
\hline \multirow{2}{*}{$\begin{array}{c}\text { Stack } \\
\text { Part }\end{array}$} & \multirow[t]{2}{*}{ Quantity } & \multicolumn{4}{|c|}{$\begin{array}{l}\text { Horizontal Excitation on } \\
\text { Dominant Frequencies [Hz] }\end{array}$} & \multicolumn{2}{|c|}{$\begin{array}{c}\text { Vertical Excitation } \\
{[\mathrm{Hz}]}\end{array}$} & \multirow{2}{*}{$\begin{array}{r}\sigma_{\max } \\
{[\mathrm{MPa}}\end{array}$} \\
\hline & & 1.0 & 5.1 & $14.5-16.0$ & 26.5 & 18.5 & 22.5 & \\
\hline \multirow{3}{*}{1} & central $\sigma_{1}$ & 22.5 & 90.5 & 3.7 & 0.8 & 2.5 & 3.2 & 132.1 \\
\hline & central $\sigma_{2}$ & 9.3 & 37.6 & 1.7 & 0.4 & 1.6 & 0.8 & 54.8 \\
\hline & surface $\sigma_{\max }$ & 22.5 & 86.7 & 3.7 & 0.7 & 2.5 & 3.2 & 126.8 \\
\hline \multirow{2}{*}{2} & surface $\sigma_{\min }$ & 26.9 & 118.9 & 5.9 & 1.6 & 1.7 & 1.2 & 172.6 \\
\hline & surface $\sigma_{\max }$ & 41.2 & 164.9 & 7.8 & 2.2 & 2.7 & 3.2 & 240.7 \\
\hline \multirow{3}{*}{3} & central $\sigma_{1}$ & 15.4 & 50.6 & 1.9 & 0.4 & 2.0 & 3.0 & 75.0 \\
\hline & central $\sigma_{2}$ & 2.7 & 49.1 & 3.7 & 0.7 & 1.3 & 0.3 & 69.7 \\
\hline & surface $\sigma_{\max }$ & 15.4 & 51.4 & 1.9 & 0.4 & 2.0 & 3.0 & 76.0 \\
\hline \multirow{3}{*}{4} & central $\sigma_{1}$ & 8.2 & 46.8 & 2.2 & 0.5 & 2.4 & 2.7 & 67.4 \\
\hline & central $\sigma_{2}$ & 3.8 & 31.4 & 2.1 & 0.5 & 1.2 & 0.1 & 44.9 \\
\hline & surface $\sigma_{\max }$ & 9.9 & 47.6 & 2.3 & 0.5 & 1.7 & 2.7 & 68.8 \\
\hline \multirow{3}{*}{5} & central $\sigma_{1}$ & 12.1 & 28.4 & 3.2 & 0.7 & 1.8 & 2.6 & 44.0 \\
\hline & central $\sigma_{2}$ & 1.6 & 67.5 & 3.4 & 0.8 & 1.0 & 0.1 & 95.6 \\
\hline & surface $\sigma_{\text {max }}$ & 12.1 & 63.7 & 3.4 & 1.0 & 1.7 & 2.6 & 91.8 \\
\hline \multirow{3}{*}{6} & central $\sigma_{1}$ & 5.5 & 16.9 & 2.1 & 0.4 & 1.6 & 2.5 & 25.4 \\
\hline & central $\sigma_{2}$ & 1.6 & 39.1 & 1.7 & 0.6 & 1.0 & 0.3 & 55.4 \\
\hline & surface $\sigma_{\max }$ & 5.5 & 39.1 & 2.1 & 0.4 & 1.2 & 2.6 & 56.0 \\
\hline
\end{tabular}

Table 2. Vibration Amplitude [mm] in Stack Parts

\begin{tabular}{|c|c|c|c|c|c|c|c|c|}
\hline \multirow{2}{*}{$\begin{array}{c}\text { Stack } \\
\text { Part }\end{array}$} & \multirow[t]{2}{*}{ Quantity } & \multicolumn{4}{|c|}{$\begin{array}{l}\text { Horizontal Excitation on } \\
\text { Dominant Frequencies [Hz] }\end{array}$} & \multicolumn{2}{|c|}{$\begin{array}{c}\text { Vertical Excitation } \\
{[\mathrm{Hz}]}\end{array}$} & \multirow[t]{2}{*}{$\begin{array}{c}\mathrm{y}_{\mathrm{nax}} \\
{[\mathrm{mm}]}\end{array}$} \\
\hline & & 1.0 & 5.1 & $14.5-16.0$ & 26.5 & 18.5 & 22.5 & \\
\hline \multirow{4}{*}{1} & $\overline{y_{x}}$ & 13.203 & 18.891 & 0.689 & 1.517 & - & 0.007 & 32.7 \\
\hline & $y_{y}$ & 0.022 & 0.046 & 0.008 & 0.001 & - & 0.007 & 0.1 \\
\hline & $y_{z}$ & 0.384 & 1.841 & 0.076 & 0.024 & 0.222 & - & 2.7 \\
\hline & $\mathrm{y}$ & 13.209 & 18.981 & 0.693 & 1.517 & 0.222 & 0.010 & 32.8 \\
\hline \multirow{4}{*}{2} & $\mathrm{y}_{\mathrm{x}}$ & 13.187 & 18.722 & 0.687 & 0.151 & - & 0.002 & 32.4 \\
\hline & $y_{y}$ & 0.011 & 0.032 & 0.004 & 0.001 & - & 0.025 & 0.1 \\
\hline & $y_{z}$ & 0.384 & 1.687 & 0.073 & 0.019 & 0.214 & - & 2.5 \\
\hline & $\mathrm{y}$ & 13.193 & 18.798 & 0.691 & 0.152 & 0.214 & 0.025 & 32.5 \\
\hline \multirow{4}{*}{3} & $y_{x}$ & 14.549 & 34.132 & 0.714 & 0.150 & - & 0.011 & 52.5 \\
\hline & $y_{y}$ & 0.329 & 0.422 & 0.146 & 0.014 & - & 0.012 & 0.8 \\
\hline & $y_{z}$ & 1.455 & 2.899 & 0.104 & 0.023 & 0.390 & - & 4.6 \\
\hline & $y$ & 14.625 & 34.257 & 0.736 & 0.152 & 0.390 & 0.016 & 52.7 \\
\hline
\end{tabular}




\begin{tabular}{|c|c|c|c|c|c|c|c|c|}
\hline \multirow{4}{*}{4} & $\mathrm{y}_{\mathrm{x}}$ & 14.658 & 35.129 & 0.770 & 0.150 & - & 0.009 & 53.8 \\
\hline & $y_{y}$ & 0.576 & 2.148 & 0.087 & 0.010 & - & 0.011 & 3.1 \\
\hline & $y_{z}$ & 0.807 & 1.802 & 0.070 & 0.016 & - & 0.311 & 2.8 \\
\hline & $y$ & 14.692 & 35.240 & 0.778 & 0.151 & - & 0.311 & 54.0 \\
\hline \multirow{4}{*}{5} & $y_{x}$ & 55.449 & 38.350 & 0.728 & 0.096 & - & 0.007 & 95.4 \\
\hline & $y_{y}$ & 2.086 & 5.522 & 0.090 & 0.010 & - & 0.007 & 8.3 \\
\hline & $y_{z}$ & 2.306 & 5.599 & 0.154 & 0.029 & - & 0.532 & 8.6 \\
\hline & $\mathrm{y}$ & 55.536 & 39.148 & 0.749 & 0.101 & - & 0.532 & 96.1 \\
\hline \multirow{4}{*}{6} & $y_{x}$ & 59.841 & 39.884 & 0.784 & 0.090 & - & 0.007 & 101.7 \\
\hline & $y_{y}$ & 1.318 & 5.599 & 0.109 & 0.012 & - & 0.006 & 8.1 \\
\hline & $y_{z}$ & 1.235 & 3.145 & 0.098 & 0.019 & - & 0.526 & 4.8 \\
\hline & $\mathrm{y}$ & 59.868 & 40.398 & 0.798 & 0.093 & - & 0.526 & 102.1 \\
\hline
\end{tabular}

\section{ASSESSMENT OF SEISMIC ANALYSIS REQUIREMENTS}

The analysis of the dynamic response of the ventilation stack structure for a seismic event reveals that of decisive significance for the dynamic response of the structure are the seismic movements of the sub-base in the region of the lowest natural frequencies of the bending vibrations in the vicinity of 1.0 and $5.1 \mathrm{~Hz}$. Although in case of seismic loads the design standards prescribe the analysis of the behaviour of the structure in the frequency range of aproximately up to $33 \mathrm{~Hz}$, the influence factor of natural modes with the frequencies over $15 \mathrm{~Hz}$ is relatively insignificant (see Tables 1 and 2).

The Czech Standard [2] prescribes the assessment of internal forces while taking into account the effect of the basic dominant frequency of the natural vibrations of the structure in superposition, but with half the weight, with further higher natural frequencies. The preceding analysis has revealed that in case of such a seismically sensitive structure as the ventilation or chimney stack the response of the structure to the basic bending natural frequency (of about $1.9 \mathrm{~Hz}$ ) need not be always dominant for the overall stress state of the structure. In our case the dominant effect is exercised by the frequency peak at 5.1 to $5.2 \mathrm{~Hz}$, i.e. the $4^{\text {th }}$ and the $5^{\text {th }}$ natural frequencies.

In standard building structures the seismic excitation produces dominant effect in its lowest natural frequency, as a rule. Should we apply this rule also to this particular case, i.e. to the bending vibrations in directions $x$ and $y$ at the frequency of about $1 \mathrm{~Hz}$, we would commit an error at the cost of safety. Higher vibration modes in standard building structures, consequently, have lower effects, as a rule, or the second lowest natural mode is comparable with the dominant basic first natural mode (in this particular case the effects of the $4^{\text {th }}$ and $5^{\text {th }}$ natural modes are comparable with the lowest two ones).

Eurocode [3] does not deal with the composition of individual frequency components of internal forces, but according to the provisions of Art. 4.1, para. 4 it characterizes the design acceleration of $0.1 \mathrm{~g}$ for a building with a chimney stack as "a low seismicity domain" for which "the application of a simplified method of seismic design is permitted" and, consequently, understimates the significance of seismic load for such a sensitive structure to a certain extent which is, as shown by the preceding computation, near the limit bearing capacity.

\section{SEISMIC RESISTANCE ASSESSMENT AND METHODS OF ITS IMPROVEMENT}

With regard to the both simplifications of the whole phenomenon of the seismically loaded structure (use of response spectra resulting from the analysis of the building and the superposition of higher natural vibration modes on the resulting response) the performed computation of deflections and internal forces is sufficiently safe.

For the dimensioning of the structure the seismic effects were superposed on the effects of the dead weight of the structure. According to Czech standards [2] the dead load due to the weight of the structure with a load factor 1.1 is superposed on seismic load with a load factor 1.0.

According to US standard [1] the dead load incl. the weight of the structure appears in this combination with the load factor 1.0. The effects of seismicity are included in the combination with the factors of from 0.65 to 1.2 
according to the type of material and the loading of the structure, further corrected by the ductility characteristics of the structure.
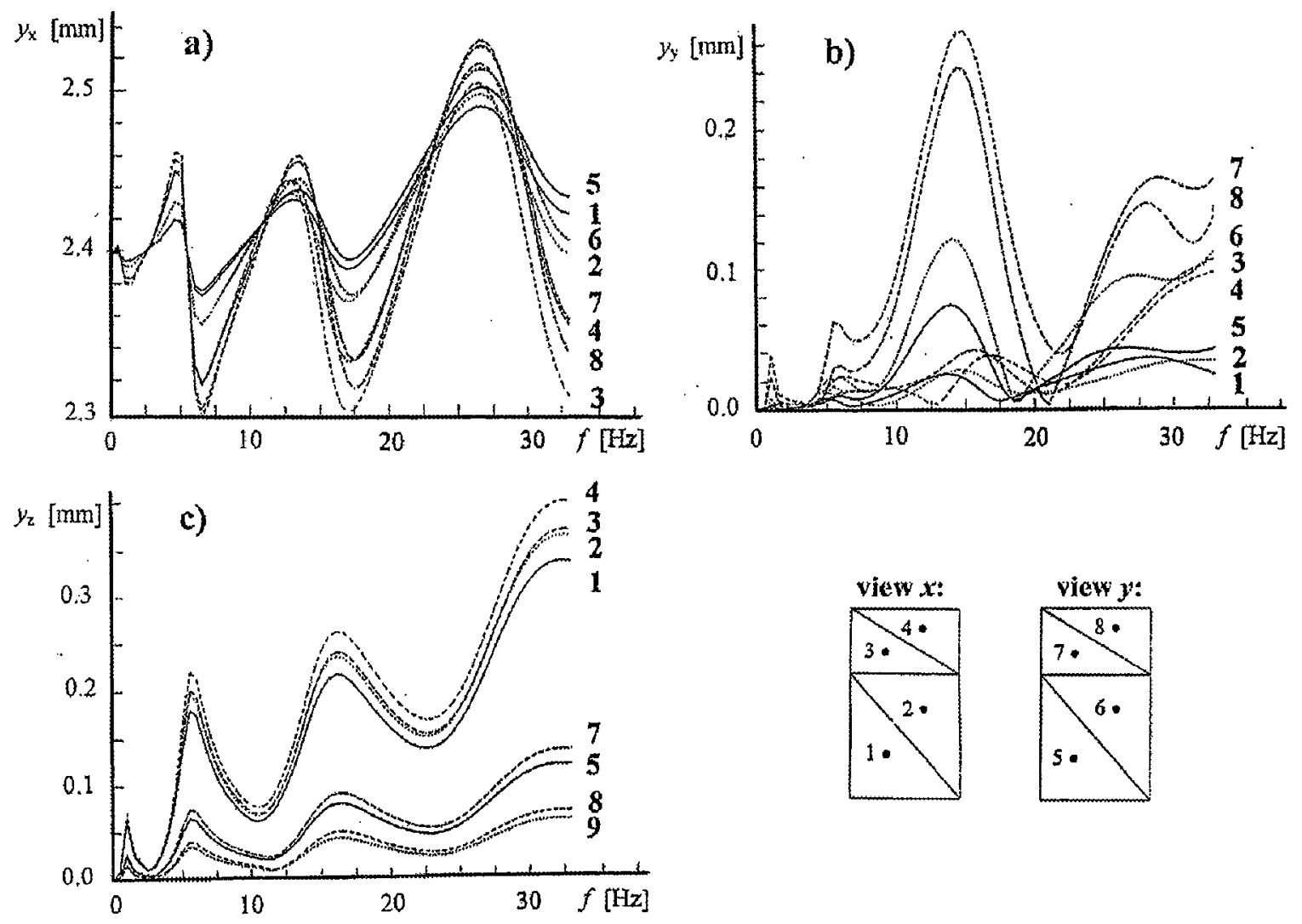

Fig. 3 Frequency Spectrum of Displacement Response

Should we assess the structure on the basis of the results of the linear elastic analyses without the possibility of plastic deformation, this stack structure, thanks to the seismic signal amplification by the building on top of which it is mounted, would mildly exceed the boundary of its seismic resistance (the yield limit of steel has been exceeded in the foundation element stiffeners). Horizontal excitation produces the highest stresses in the foundation element of the chimney stack, viz its vertical stiffeners. The effect of seismic design load, amplified by the transmission characteristics of the building, produces plastic deformations in the margins of these stiffeners and stress redistribution between the stiffeners and the exterior skin plate of the stack foundation element (increase of stress state in other stiffeners and the stack skin). According to computation results with the exception of the plasticized stiffeners of the most highly stressed foundation part of the stack all other structural parts of the stack are stressed by seismic load in the elastic domain of material deformation.

On the basis of the given seismic load data (Fig. 2) the ventilation stack structure has no significant seismic resistance reserves. These reserves can be estimated at some $10 \%$ with reference to material characteristics used in design standards. Actual reserves will be obviously somewhat higher due to the introduced conservative initial assumptions of stack behaviour under dynamic load and the conservative definition of the transmission characteristics of the building forming the basis of the computation of the seismic reliability of the ventilation stack.

The simplest method of improvement of seismic resistance of the ventilation stack is the application of higher quality steel (such as S 355) or more thorough stiffening of the foundation element. The latter, however, calls for caution, as more significant stiffening of this part of the stack structure would produce higher stresses in the stack skin above the foundation element. Another, obviously more favourable way of improving the seismic resistance is 
the change of the whole structural design of the stack which can be effected only if the whole structure is still in the design stage. In existing structures, on the other hand, it is more advantageous to provide the structure with a dynamic vibration absorber tuned to the dominant response frequencies $(0.1$ and $5.1 \mathrm{~Hz})$, thus reducing their participation in the overall response of the structure.

Table 3. Screw Support Forces [kN]

\begin{tabular}{|l|c|c|c|c|c|c|c|}
\hline \multirow{2}{*}{ Quantity } & \multicolumn{4}{|c|}{$\begin{array}{c}\text { Horizontal Excitation on } \\
\text { Dominant Frequencies [Hz] }\end{array}$} & $\begin{array}{c}\text { Vertical Excitation } \\
{[\mathrm{Hz}]}\end{array}$ & $\begin{array}{c}\mathrm{F}_{\max } \\
{[\mathrm{kN}]}\end{array}$ \\
\cline { 2 - 8 } & 1,0 & 5,1 & $14,5-16,0$ & 26,5 & 18,5 & 22,5 & \\
\hline Axial Force $\mathrm{N}_{\mathrm{x}}$ & 82,4 & 345,2 & 15,1 & 2,4 & 5,9 & 10,6 & 502,4 \\
\hline Tangential Force $\mathrm{Q}_{\mathrm{y}}$ & 15,4 & 73,6 & 3,9 & 1,2 & 0,1 & 0,1 & 106,5 \\
\hline
\end{tabular}

\section{CONCLUSION}

The goal of the paper was to show on an example of the computation of the seismic response of a steel ventilation stack structure the advantages of modal analysis with particular reference to the specific characteristics of a steel cantilever stack structure which is very sensitive to low-frequency seismic excitation.

The analysis has revealed explicitly that in the structure of this type the lowest natural vibration mode need not be the dominant mode for the design of the structure, but may be replaced with one or several higher modes which determine the seismic resistance of the structure. Particularly in the structures the seismic load of which is mediated by the transmission characteristics of another structure (in this particular case the building on top of which the stack is mounted) this procedure is very useful for the correct design or assessment of the structure.

\section{ACKNOWLEDGEMENTS}

This research was supported as a part of research projects of the GAČR No 103/00/0705 „Analysis of the risk of failure under accidental action of seismic and impact pressure waves“ and CEZ: J04/98:210000029 „Risk assessment and reliability of engineering systems" for which the authors would like to thank the Agencies.

\section{REFERENCES}

1. ANSI/ASCE 7-93, "Minimum Design Loads for Buildings and Other Structures," ASCE, New York, 1994.

2. ČSN 73 0036, "Seismic Load of Structures (in Czech), " CSNI, Praha, 1973.

3. ČSN P ENV 1998-1-1, 73 0036, Eurocode 8, 1993, "Design Provisions for Earthquake Resistance of Structures Part 1-1: General Rules - Seismic Actions and General Requirements for Structures, " CEN, Brussels, 1993.

4. ČSN 73 1401, "Design of Steel Structures (in Czech), " Praha, ČNI 1998.

5. ISO 3010, "Bases for Design of Structures - Seismic Actions on Structures," ISO, 1988.

7. Kennedy, R. P. et al., "Design and Evaluation Guidelines for Department of Energy Facilities Subjected to Natural Phenomena Hazards, " Report UCLR-15910, LLNL, Livermore, 1990.

8. Makovička, D., "Ductile Behaviour of Dynamically Loaded Structures," Structural Dynamics Eurodyn '99, A. A. Balkema, Rotterdam, 1999, pp. 1136-1140.

9. Newmark, N. M., Hall, W. J., "Development of Criteria for Seismic Review of Selected Nuclear Power Plants," Report NUREG/CR-0098, NRC, Washington, 1978. 